\title{
Wear Behavior of Surface Treated X45MoCrV5-3-1 Tool Steel at Room and Elevated Temperatures
}

\author{
G. Aktaş, Ş. Polat*, Ş.H. Atapek \\ Kocaeli University, Department of Metallurgical and Materials Engineering, 41380 Kocaeli, Turkey
}

\begin{abstract}
The aim of this study is to compare the wear behavior of X45MoCrV5-3-1 tool steel, used as die material in aluminum extrusion, after single treatment (CrN coating) and duplex treatment (nitriding and CrN coating). Gas nitriding and physical vapor deposition were used as processing techniques and wear tests were carried out at both room and elevated temperatures. A "ball-on-disc" type tribometer was used for room temperature tests, utilizing $\mathrm{Al}_{2} \mathrm{O}_{3}$ ball as counterpart. In order to simulate the wear conditions during extrusion, hot wear tests were carried out at $450{ }^{\circ} \mathrm{C}$ using "block-on-cylinder" type tribometer against AA 6080 material. Worn surfaces were studied by microscopy to reveal the wear characteristics of treated steels. It was found that (i) duplex treated steel, having higher friction coefficient at room and elevated temperature, had higher wear resistance, (ii) at room temperature single treated steel exhibited higher volume loss than the duplex treated one, (iii) at elevated temperature duplex treated steel revealed a stable coating layer, whereas micro cracks were observed on the surface of the single treated steel.
\end{abstract}

DOI: $10.12693 /$ APhysPolA.127.1221

PACS: 81.05.Bx, 81.65.-b, 81.40.Pq, 81.70.-q

\section{Introduction}

From past to present, in order to eliminate the wear problem, industry needs to develop hard die surfaces. The surfaces can be hardened by heat treatments, nitriding or coating thin films with physical vapor deposition (PVD) or chemical vapor deposition (CVD) processes [1-3]. Researchers concluded that $\mathrm{CrN}$, AlTiN coatings and their enhanced applications like $\mathrm{AlCrN}$, Al$\mathrm{CrSiN}$ improve the wear resistance of dies used in extrusion process [4-7]. For a coated material, the load carrying capacity of the coating/substrate becomes important. The way to increase the load carrying capacity of coating/substrate system without increasing the thickness is to obtain a hard substrate. Studies show that the coatings on harder substrate have better wear resistance than those on softer substrate $[8,9]$. So as to obtain hard substrate, researchers applied nitriding process on substrate surfaces and they tried to use diffusion zone as substrate in coating process $[5,10,11]$. In fact, studies showed that with nitriding process, load carrying capability of the coating/substrate was developed and chemical stability of dies against aluminum was enhanced $[4,10]$. In this work, wear behavior of X45MoCrV5-3-1 tool steels coated by various methods was investigated. In addition to room temperature wear tests, high temperature tests were performed at $450{ }^{\circ} \mathrm{C}$ in order to determine the wear behavior of steels in extrusion conditions. Heat treated and nitrided steels were also investigated as control group to understand the changes in wear resistance.

* corresponding author; e-mail: sydpolat@gmail.com

\section{Materials and method}

In the experimental study, X45MoCrV5-3-1 (0.45 C, $0.30 \mathrm{Mn}, 0.30 \mathrm{Si}, 3.00 \mathrm{Cr}, 5.00 \mathrm{Mo}$ and $1.00 \mathrm{~V}$ wt.\%) hot work tool steel was used as substrate material. To make a comprehensive assessment in the study, steel specimens were prepared in the following manner; (i) a suggested conventional heat treatment process was applied to obtain hard and tough steel substrates [12], (ii) gas nitriding process was carried out in ammonia atmosphere and steels were heated at $585^{\circ} \mathrm{C}$ for $6 \mathrm{~h}$ and cooled in $1.1 \mathrm{bar}$ air, (iii) $\mathrm{CrN}$ coating as single surface treatment and (iv) nitriding $+\mathrm{CrN}$ coating as duplex surface treatment were applied to tool surfaces. Prior to the coating process, white layer formed due to nitriding was ground using 1000 mesh $\mathrm{SiC}$ paper. The deposition of $\mathrm{CrN}$ coating was carried out by Novatech NVT-11 model cathodic arc PVD machine, in high purity nitrogen at a pressure of 6.5 mTorr. A bias voltage of $110 \mathrm{~V}$ was applied to the substrate and process was carried out for 70 minutes in order to obtain $\sim 2 \mu \mathrm{m} \mathrm{CrN} \mathrm{coating.} \mathrm{As} \mathrm{it} \mathrm{is} \mathrm{well} \mathrm{known,}$ the surface hardness is an important factor in enhancing the wear resistance of die materials. The hardness of steel after heat treatment (HW1) was measured as $504 \mathrm{HV}_{0.01}$. This value is higher than those of DIN 1.2343 and DIN 1.2344 hot work tool steels used as die materials in aluminum extrusion [13-15], making it favorable among the hot work tool steels whenever the high surface hardness is desired for the mechanical requirements. Nitriding and coating processes have increased the surface hardness even further. The measured hardness values were $755 \mathrm{HV}_{0.01}, 1739 \mathrm{HV}_{0.01}$ and $2018 \mathrm{HV}_{0.01}$ for heat treated + nitrided (HW2), heat treated $+\mathrm{CrN}$ coated (HW3) and heat treated + nitrided $+\mathrm{CrN}$ coated (HW4) steels, respectively.

Wear tests at room temperature were performed using 
a "ball-on-disc" type tribometer and $\mathrm{Al}_{2} \mathrm{O}_{3}$ balls were selected as counterpart. In these tests, rotational speed, normal load and total sliding distance known as typical wear parameters were adjusted as $150 \mathrm{rpm}, 20 \mathrm{~N}$ and $150 \mathrm{~m}$, respectively. The high temperature wear tests were carried out at $450{ }^{\circ} \mathrm{C}$ using "block-on-cylinder" type tribometer against AA 6080 material to simulate the wear conditions during extrusion. The wear parameters were $0.27 \mathrm{~m} / \mathrm{s}, 70 \mathrm{~N}$ and $2000 \mathrm{~m}$. After all tests, worn surfaces were examined using Nikon Eclipse L150A light microscope (LM) and Jeol JSM-6060 scanning electron microscope (SEM). The depth and width values of worn surfaces were determined using KLA Tencor P-6 model profilometer. IXRF model energy dispersive spectrometer (EDX) was used for microanalysis.

\section{Results and discussion \\ 3.1. Microstructural characterization}

The conventionally heat treated X45MoCrV5-3-1 steel (HW1) has tempered martensitic matrix including globular M6C (Mo-rich) carbides (Fig. 1a). Combination of tempered martensite and alloy carbides provides high hardness and sufficient toughness. During nitriding process, a white layer is formed on the surface and $\mathrm{N}$ atoms diffuse towards the matrix to form a diffusion layer including nitride precipitates [2]. Figure 1b shows the cross-section of nitrided steel (HW2) where white layer is clear, and EDX spot analyses indicate that $\mathrm{N}$ content decreases gradually from surface to matrix, as expected. The cross-section of $\mathrm{CrN}$ coated steel (HW3) reveals that the coating has a thickness of about $2 \mu \mathrm{m}$ and the spot analyses exhibit the variation of $\mathrm{Cr}, \mathrm{N}$ and Fe concentrations (Fig. 1c). Figure 1d shows clearly a stable diffusion layer in the cross-section of duplex treated steel (HW4).

\subsection{Evaluation of wear tests}

Friction coefficient versus sliding distance diagrams are shown in Fig. 2. At room temperature tests, HW4 steel having the highest surface hardness exhibits the highest friction coefficient value (Fig. 2a). Contact area decreases but shear strength increases with increasing hardness of the plate material, thus friction coefficient gets higher [3]. HW1 and HW3 steels have similar coefficient of friction values. Based on the curves and hardness values, it can be emphasized that (i) $\mathrm{Al}_{2} \mathrm{O}_{3}$ ball embeds into $\mathrm{HW} 1$ steel surface, which does not have any hard layer, and the contact area becomes wider than that of HW3, having CrN coating, (ii) however, since the ball is not embedded into the surface of HW3 steel as much as HW1 this results an increase of shear strength. As a result of the balance between contact area and shear strength, the friction coefficient values of HW1 and HW3 steels are close to each other. On the other hand nitrided HW2 steel has the lowest friction coefficient due to its high surface roughness value. Its surface was ground using 1000 mesh $\mathrm{SiC}$ paper before nitriding, whereas HW3 and HW4 steels were polished to form a mirror like surface prior to coating. From tribological point of view, (i) the
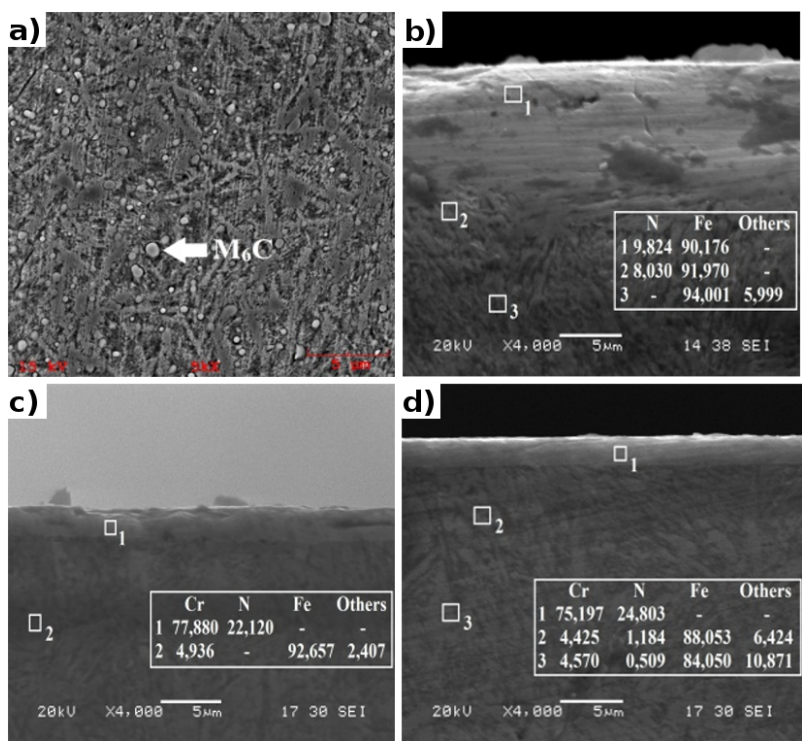

Fig. 1. SEM micrographs showing the etched ( $3 \%$ nital) microstructure of (a) HW1, (b) HW2, (c) HW3, (d) HW4.
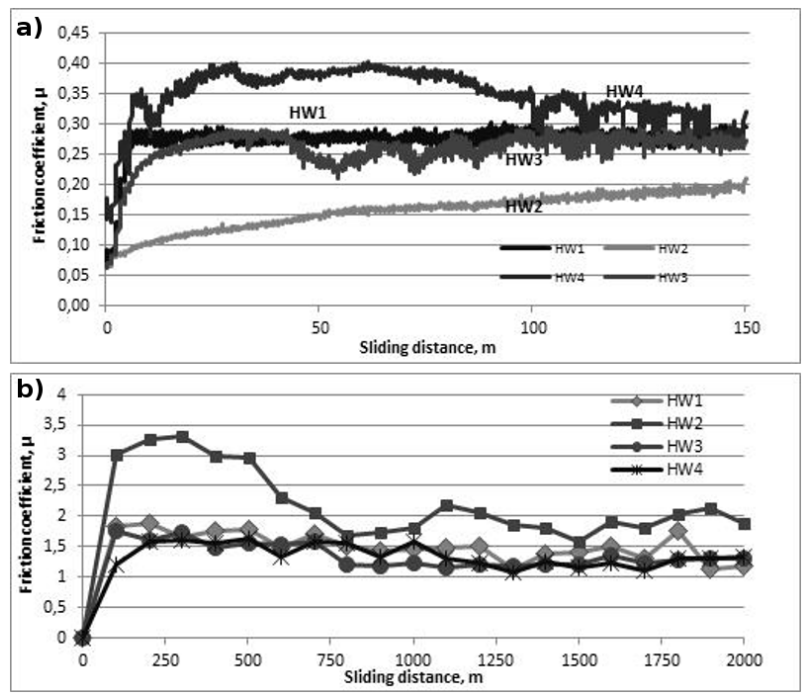

Fig. 2. The diagrams showing the mean friction coefficient as a function of sliding distance obtained by (a) "ball-on-disc" type tribometer at room temperature, (b) "block-on-cylinder" type tribometer at $450{ }^{\circ} \mathrm{C}$.

surface roughness reduces the contact area and friction coefficient decreases, (ii) however, after asperities rupture, the asperities on the surface cause micro ploughing effect and increase the friction coefficient [3]. These concepts explain the curvilinear change in friction coefficient as a function of distance, for nitrided HW2 steel, under dry sliding conditions. The elevated temperature tests show that all steels have higher friction coefficient values than those obtained at room temperature (Fig. 2b). At $450{ }^{\circ} \mathrm{C}$, aluminum has strong tendency to adhere to steel and forms adhesive layer leading to quite high friction 
coefficient $[4,10]$. Thus, steels have friction coefficient values higher than 1.0 at this temperature. The roughness of nitrided steel (HW2) causes higher adherence of aluminum to steel surface and a three-body wear mechanism occurs. This explains why HW2 nitrided steel has the highest friction coefficient for the whole sliding distance. Since $\mathrm{CrN}$ coating reduces the aluminum affinity $[4,10]$, the steels coated with $\mathrm{CrN}$ (HW3 and HW4) have close friction coefficient values and also their values are lower than those of HW1 and HW2.

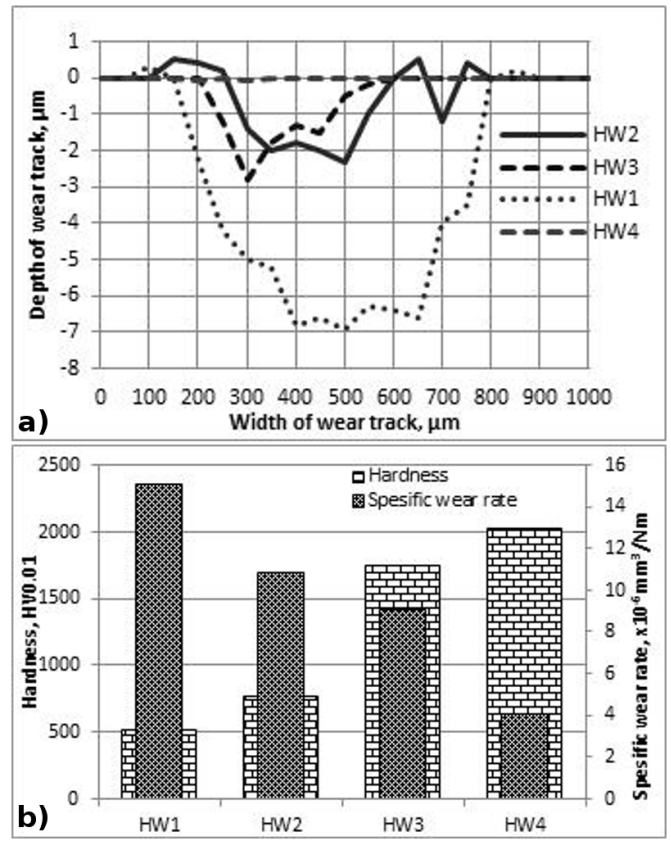

Fig. 3. (a) The profilometer results showing wear track depth and width, (b) the diagram showing the relationship between specific wear rate and hardness.
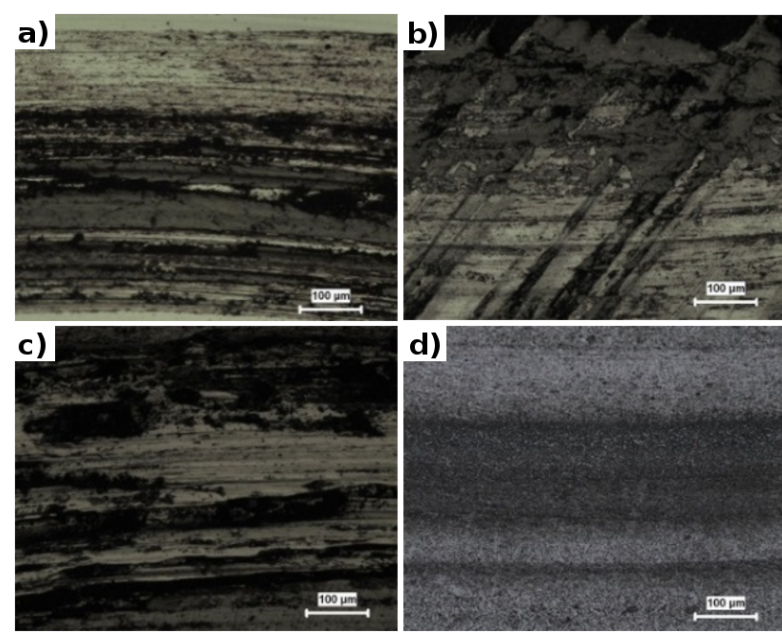

Fig. 4. LM images showing worn surfaces of (a) HW1, (b) HW2, (c) HW3, (d) HW4 steels tested at room temperature.
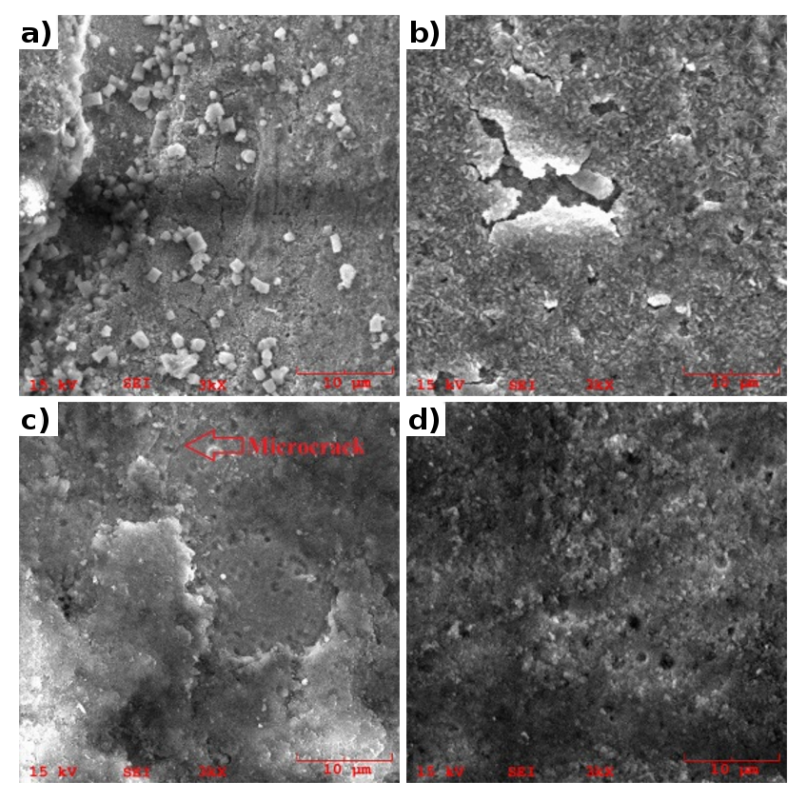

Fig. 5. SEM images showing worn surfaces of (a) HW1, (b) HW2, (c) HW3, (d) HW4 steels tested at $450{ }^{\circ} \mathrm{C}$.

Figure 3a shows the depth and width of wear tracks measured by profilometer. The diagram was drawn taking depth and width values at $50 \mu \mathrm{m}$ intervals. Figure $3 \mathrm{~b}$ indicates the relationship between specific wear rate calculated using $W_{r}=V / F S$ equation $\left(W_{r}\right.$; spesific wear rate, $V$; volume loss, $F$; normal load and $S$; sliding distance) and hardness. The measured volume loss $\left(\mathrm{mm}^{3}\right)$ values are $426 \times 10^{-4}, 325 \times 10^{-4}, 271 \times 10^{-4}$ and $121 \times 10^{-4}$ for HW1, HW2, HW3 and HW4 steels, respectively. According to the diagrams given in Fig. 3, HW1 steel having the lowest hardness exhibits the highest wear track depth and width as well as the highest specific wear rate. By the virtue of nitriding process before coating, bonding between substrate and coating is enhanced and therefore load carrying capacity of substrate/coating system is improved $[16,17]$. As a result, HW4 steel shows quite low volume loss and the minimum specific wear rate. During the wear test at $450{ }^{\circ} \mathrm{C}$, metal transfer occurs on steels due to the adhesion between steel block and AA 6080 cylinder. The surfaces were cleaned with $\mathrm{NaOH}$ solution after the test, but volume loss or weight loss could not be determined. In order to understand if any failure occurred or not, worn surfaces were investigated by SEM.

\subsection{Worn surfaces investigations}

Figure 4 shows the worn surfaces of HW1, HW2 and HW3 steels exhibiting both abrasive tracks and adhesive layers as a result of the interaction with $\mathrm{Al}_{2} \mathrm{O}_{3}$ ball at room temperature. However, there is no severe track/layer on the surface of HW4 steel (Fig. 4d). This indicates that duplex treatment develops the load carrying capacity during dry sliding. The worn surfaces 
formed at elevated temperature also were examined by SEM (Fig. 5a-5d). As it is well known, outer boundary layer includes ferrous oxide particles/layers like $\mathrm{Fe}_{2} \mathrm{O}_{3}$ and $\mathrm{Fe}_{3} \mathrm{O}_{4}$ as a function of temperature and degree of friction [2]. The particles can be clearly seen on the worn surface of HW1 steel that has the highest volume loss (Fig. 5a). Adhesion of aluminum to steel is possible at the test temperature and the worn surfaces of HW2, HW3 and HW4 steels reveal adhered aluminum layers (Fig. 5b-5d). On the other hand, microcracks were observed on the coating of HW3 steel, whereas no cracking was seen on the coating of HW4 steel. This indicates that the load carrying capacity of $\mathrm{CrN}$ coating having no nitriding/diffusion layer is not sufficient at $450{ }^{\circ} \mathrm{C}$ under normal load.

\section{Conclusion}

In this study, the wear behavior of X45MoCrV5-3-1 tool steel was investigated as a function of heat/surface treatment and under different tribological conditions. Duplex treated HW4 steel has the lowest volume loss and thus, lowest specific wear rate during the test carried out at room temperature. At elevated temperature it revealed a stable coating layer with no microcracks. Therefore, applying duplex treatment (nitriding $+\mathrm{CrN}$ coating) on heat treated tool materials, used in Al extrusion at elevated temperature, is favorable for reducing failure due to wear.

\section{References}

[1] G. Roberts, G. Krauss, R. Kennedy, Tool Steels, 5th Edition, ASM International, Ohio 2000.
[2] B.G. Mellor, Surface Coatings for Protection Against Wear, Woodhead Publishing Limited and CRC Press, Boca Raton 2006.

[3] K. Holmberg, A. Matthews, Coatings Tribology, Properties, Techniques and Applications in Surface Engineering, 2nd Edition, Elsevier, Oxford 2009.

[4] Y. Birol, Tribol. Int. 57, 101 (2013).

[5] R. Hoy, J.D. Kamminga, G.C.A.M. Janssen, Surf Coat. Tech. 200, 3856 (2006).

[6] J.L. Mo, M.H. Zhu, A. Leyland, A. Matthews, Surf. Coat. Tech. 215, 170 (2013).

[7] K. Lukaszkowicz, A. Czyżniewski, W. Kwaśny, M. Pancielejko, Vacuum 86, 1186 (2012).

[8] J. Eriksson, M. Olsson, Surf. Coat. Tech. 205, 4045 (2011).

[9] M. Vite, M. Moreno-Ríos, E.A. Gallardo Hernandez, J.R. Laguna-Camacho, Wear 271, 1273 (2011).

[10] M. Pellizzari, Wear 271, 2089 (2011).

[11] R. Rodriguez-Baracaldo, J.A. Benito, E.S. PuchiCabrera, M.H. Staia, Wear 262, 380 (2007).

[12] http://http://www.schmolz-bickenbach.us/ fileadmin/files/schmolz-bickenbach.us/ documents/Tool_Steel_Data_Sheets/Thermodur_ 2999.pdf.

[13] Ş. Polat, S..H. Atapek, E. Türedi, G. Aktaş, Mater. Test. 55, 163 (2013).

[14] V. Leskovsek, B. Sustarsic, G. Jutrisa, J. Mater. Proces. Technol. 178, 328 (2006).

[15] A. Bahrami, S.H. Mousavi Anijdan, M.A. Golozar, M. Shamanian, N. Varahram, Wear 258, 846 (2005).

[16] C.-W. Cho, Y.-Z. Lee, Surf. Coat. Tech. 127, 59 (2000).

[17] B. Škoric, D. Kakaš, M. Rakita, N. Bibić, D. Peruškob, Vacuum 76, 169 (2004). 